\title{
Stovall Home Products: Practicing Prudence to Avoid Liability
}

Katherine M. Erdman

Herbert W. Hildebrandt

University of Michigan, Ann Arbor

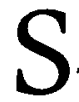

TOVALL HOME PRODUCTS, a large, highly regarded, publicly held firm based in St. Louis, manufactures and markets a variety of cleaning and care products for homes and clothing. Because these product categories are hotly competitive, Stovall advertises widely, runs frequent promotions, and emphasizes customer service strongly.

White-n-Brite Liquid Bleach, Stovall's flagship brand, has been on the market for seventy-five years and is judged best in its category by all leading consumer product rating publications. The company tests the product is tested continually for use with various new fabrics, fiber blends, and finishes. It also updates directions periodically to improve clarity and guide customer product use. Three product sizes retail for $\$ 2.59, \$ 4.29$, and $\$ 6.59$ respectively.

In addition to its products, Stovall is recognized for outstanding management and rigorous, innovative managerial development. Many seek jobs at Stovall as a way to learn the consumer products industry. After completing your degree in management, you began work six weeks ago as an assistant brand manager on White-n-Brite Liquid Bleach.

\section{Consumer Services Background}

Stovall's top priority is satisfying its customers. After new hires in the marketing department have completed initial group orientation, company policy requires that they participate in a two-week "customer perspective" rotation. You have just spent one week accompanying one of the firm's district sales managers on calls to laundry products buyers for major customers, such as supermarket chains and mass merchandisers. This week you will work with the company's Con- 
sumer Services Department gaining first-hand experience and insight in dealing with individual consumers' product inquiries.

This morning, Tom Simmons, White-n-Brite Liquid brand manager and your boss, introduced you to Carol Smith, Director of Consumer Services, and her staff, with whom the brand teams work closely. In welcoming you, Carol emphasized that serving customers well demands a high degree of teamwork within the company as well as with outside sources.

"For example," she explained, "we work closely with Research \& Development (R\&D) and their test laboratories on product ideas, use, and problem issues. We also work with Marketing, Sales, and Communications on product labels, directions, promotions, advertising, and publicity. Then there is the Legal Department. Besides giving us input on labels and such, they help with trademark protection and prudence in providing product information advice. In addition, we cultivate an extensive network of contacts with manufacturers and marketers of clothing, carpeting, and other items which our products are used to clean. Touching base with these colleagues will help you appreciate the many types of expertise often needed to provide a helpful reply. And reading customer letters yourself will give you a far greater appreciation for what customers think about the brand you work on and how they use it than if you read reams of reports on trends and usage."

Carol then turned you over to Helen Anderson, Laundry Products Service Manager. "Our fundamental goal is to enhance customers' positive opinions of our company, products, and service so that we keep our excellent reputation and market leadership," Helen said. "The company established this department in 1922, when we introduced White-n-Brite Liquid Bleach. The idea was to help customers use our products correctly and prevent problems whenever possible. It's much less expensive to keep a satisfied customer than to attract a new customer or win back a dissatisfied one."

After you and Helen stopped at the coffee machine, she continued. "The Stovall approach has always been to treat customers well, even when their complaints seem unmerited. Dealing in a pleasant, helpful way with customer complaints pays off. Industry surveys show that three-quarters of those customers whose complaints are resolved will continue to buy a company's products. Even a third of those whose 
complaint is not resolved will buy again if their problem receives prompt, courteous attention. But fewer than 10 percent will buy again if they don't know who to contact about the problem or are unhappy about the service-or if contacting the company is simply too much trouble."

"As I remember it," you said, thinking back to marketing coursework, "one dissatisfied customer tells an average of about ten more."

"True," replied Helen. "So our first job is to make sure that contact with us is quick and pleasant. That's why, for example, we give the address and telephone number of Stovall's Consumer Services on all labels and invite customer inquiries. We also train our service representatives constantly."

"What's your biggest challenge?" you asked.

"Dealing successfully with customers whose requests or problems can't be resolved the way they want. On average, that's about 5 to 10 percent of the total inquiries we receive about established products. In fact, since your rotation lasts just a week in Consumer Services, we prefer to work with this type letter because you learn more and you learn it faster."

"So," you ask, "how do you deal with customers when you can't readily set things right?"

"First, you should identify the problem," Helen said briskly. "Then, decide whether it can be resolved and, if so, how and who should do what. Next, explore who is responsible for the problem. 'Responsible' means 'caused' or 'at fault' and it carries legal implications, so careful consideration is important. Finally, in writing your response, think about both facts and feelings. That is, try to imagine what happened and how the customer feels about it."

"Sounds reasonable," you observed.

"So, let's get started by looking at some specific complaints," Helen continued. "Here's a letter that arrived this morning from Anne Thompson of Tallahassee, Florida. Take a minute to read it" (see Figure 1, p. 161).

After reading through the short letter twice, you looked up.

"So," asked Helen, "what do you see as the problem?"

"Well," you replied, "Thompson's white jacket now has not only the coffee stains that White-n-Brite didn't remove but also discolored yellow areas around the spots that she says White-n-Brite caused. I 
wonder how that happened! I've spilled coffee on my clothes a few times myself, but I didn't have any big problems getting the stains out. Why do you suppose she couldn't remove them from this particular jacket?"

"Good!" Helen said. "First, you need to find out some specific information about the jacket. We state clearly on the White-n-Brite label those fabrics on which our bleach can and cannot be used. We also caution consumers about non-bleachable finishes and treatments (see Figure 2, p. 162). Since Ms. Thompson doesn't identify the jacket fabric or refer to its care label instructions, you'll need to check with the manufacturer. Now I happen to know that the Sportique line of clothes that Ms. Thompson refers to here is made by SporTTogs. Our contact there is John Lopez; here's his telephone number. You'll probably find him quite helpful.

"Second," Helen continued, "Ms. Thompson's description of 'treated areas' sounds like she may have used White-n-Brite as a spot remover, something that is explicitly forbidden by the product label. Jackie Lee, manager of the Laundry Products Lab, can help you figure out what probably happened-and what, if anything, can be done."

You made a note to check with the Laundry Products Lab.

"Third, Ms. Thompson wants us to pay for the ruined jacket. There are several legal issues here, like whether or not the product was used according to directions. Ray Haines in the Legal Department can help you on that. And finally - whether or not we can reimburse her-how can we retain Ms. Thompson as a customer? That's Consumer Services' job, so when you've finished up with the manufacturer, the Laundry Lab, and Legal, come back to me."

\section{Investigation of the complaint}

Back at your desk, you re-read Ms. Thompson's letter. Then, after making appointments with Jackie Lee and Ray Haines, you telephoned John Lopez at SporTTogs. Luckily he was in, so you introduced yourself and explained the problem.

"Let me check our data on that line," John said. "Hmmm, here we go. The new Sportique line is made of a cotton-polyester blend. However, it's treated with a resin-based, stain-resistant finish that's not compatible with either dry or liquid bleaches."

"What does your care tag say?" you asked. 
"Let me check ... Hmmmm ... Warns against using bleach."

"Can you give me the specific wording?"

"Yes, here it is. It says, 'Wash in cold water, delicate cycle. Dry permanent press. Do not use bleach.' Couldn't be clearer than that."

"Well," you said, remembering a favorite cotton sweater your kid sister had inherited after your first college trip to the local laundromat, "if the instructions weren't hidden in the side seams where people can't find them..."

John Lopez groaned. "The care tags are in the side seams because that's where customers want them. They claim care tags in the neck seam are uncomfortable."

"Okay, you've convinced me," you laughed. "And thanks very much for your help on the Sportique line. It's clear you warned the consumers against bleaching."

Next, you walked to the Laundry Products Lab, introduced yourself to the manager, Dr. Jackie Lee, and shared Ms. Thompson's letter as well as John Lopez's information about the garment. After a moment's thought, Jackie said, "Obviously, using bleach was against garment care tag directions in this case. White-n-Brite's label tells consumers to follow garment care tags before using bleach. Also, Thompson's letter sounds as though she used White-n-Brite as a spot remover. See, right here she says, 'In the treated areas around the stains.'"

"Our label cautions against using the product as a spot remover?" you asked.

"Oh, yes," Jackie replied. "The White-n-Brite label makes it very clear that our bleach can't be used as a local spot remover. Has for years. But you'd be amazed how many people don't read directions!"

"So from what we can tell, I guess this stained jacket is really Ms. Thumpson's problem, not Stovall's," you said. "She's not going to like to hear that! Anything I can suggest in the letter to help her out?"

"Well, there're two possible approaches-though of course we can't guarantee either will work. First, she can try to remove the stain and discoloration herself by presoaking the entire jacket-let me emphasize, the whole jacket-for about 20 minutes. Then she should rinse it thoroughly in cold water."

"Let me jot down the exact details," you said, pulling your pencil from your shirt pocket and taking out your notepad. 
"Okay," Jackie replied. "For garments with resin-based finishes, we've found one solution more effective than most. The solution has three ingredients: one gallon of cold water, two tablespoons of

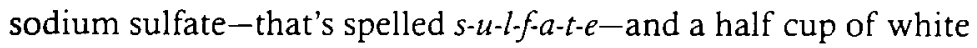
vinegar. By the way, sodium sulfate can be purchased at a drugstore or a photo supply shop."

"What then?" you asked, writing furiously.

"She should mix the ingredients thoroughly. Then she should immerse the whole jacket for about 20 minutes-immersing the whole garment will help to even out the color. Oh, and if one batch of solution doesn't cover the garment, she should double the solution."

"And then she rinses it?"

"Yes. She can either rinse the jacket thoroughly by hand or-and this is easier-run it through her washing machine's rinse cycle in water only. Emphasize 'water only, don't add anything at all."

"And then?" you asked.

"Then she should hang the jacket to drip dry."

"And what's the second approach?" you prompted.

"She can send it to us here at the Laundry Products Lab and we'll see what we can do," Jackie replied. "This might take several weeks, since we'll need to fit it into our schedule. But we could also try a wider variety of processes here than she could at home. The choice is hers. By the way, if she decides to send it to us, Stovall will pay the postage."

'Thanking Jackie, you then met with lawyer Ray Haines in Legal. He read the letter and listened to a summary of your conversations with John Lopez at SporTTogs and Jackie Lee in the Laundry Lab.

"Sounds as though you know what to say at this point," Ray observed. "Now the focus is on how to say it, which, by the way, is just as important. Because the Consumer Services Department represents the company, Stovall is legally responsible for your advice about any product we manufacture. Legal's role is to help you understand and observe, on a case-by-case basis, the fine but clear line between being sympathetic about the customer's problem, on the one side, and implying or taking responsibility for it, on the other."

"Could you explain that 'fine line' a little further?" you asked.

"Sure," replied Ray. "Being sympathetic means being courteous, clear, and helpful where possible, even when you cannot do what the 
customer wants. In contrast, implying or taking responsibility means either suggesting or stating a connection between use of the product and the undesired outcome. Sometimes you make a connection without realizing it. It's very easy, for example, to pick up phrasing used in the customer's letter without thinking how it might be understood when appearing in a company document."

Leaning back in his chair, Ray continued. "We stand behind our products when they are used as directed. But it's important to be certain about the facts. When a customer says there is a problem, check the situation out. For example, if a customer says that one of our products has damaged clothing or carpet, we should check that the product was being used according to directions. If the description leaves us in doubt, we could ask that the item or item manufacturing code be sent to us at our expense. If the product has not performed as stated and promoted, we should take appropriate steps to compensate the customer. But we must be careful not to take responsibility in circumstances where it's not appropriate, because that action could set a precedent for company liability."

"Could you give me an example?"

"Well, say the product label says not to use it on silk," Ray said expansively. "If we compensated some customers for damage to silk garments, we would have set a precedent of paying for damaged silk clothing, despite the directions prohibiting such use. If we decided to stop that practice and were sued, the court might well rule that we could not fail to pay this particular claim when we have paid others of the same type."

"How can I be sure my wording doesn't cross the line-doesn't take responsibility where it isn't appropriate?" you wondered.

"'Be prudent,' as we say," smiled Ray. "Think about whether the words you have used reflect exactly the meaning you intended. If different people read it, could they get distinctly different impressions? Another way to review your language is to ask yourself, 'If this letter were printed in a newspaper, might the public form negative opinions about the company?' If your answer is yes, then you need to revise. Of course, if you are really uncertain, the short answer is to check with an expert. At Stovall, you could go to an experienced Consumer Services manager-they know a great deal, but still check with us if they have any doubts. Or you can check with Legal directly. With 
an established product like White-n-Brite, Consumer Services has a lot of experience, so the managers will be able to answer most of your questions."

Back in Consumer Services, you dropped by Helen Anderson's office again. "Lots of good input," you said. "Before I start drafting, can you suggest any ways to build customer relations with Ms. Thompson besides thinking about how she will respond to what I say?"

"Sure. Take a look at our booklets rack; you can enclose those you think she might be interested in (see Figure 3, p. 163). Also, we have single-use samples for some new products, plus introductory in-store coupons for purchase of a new carpet care product and the new air freshener aromas."

"Thanks," you replied. "Oh, by the way, how long should this letter be? It seems like there's a lot to tell this customer."

"Typically we try to say everything in a page or less," Helen smiled. "I'll be looking forward to seeing your draft." 
2567 Gulf Shores way

Tallahassee, FL 00000

September 24,0000

Carol Smith, Director

Consumer Services Department

Stovall Home Products

1247 Oak Avenue

st. Louis, MO 00000

Dear Ms. Smith:

Yesterday I used White-n-Brite Liquid Bleach to remove coffee stains from my brand-new white sportique jacketand it didn't work. In the treated areas around the stains (which didn't come out), the material has turned an ugly yellow. It looks awful! Since the jacket was new and it's now ruined, I expect stovall to refund the cost ( $\$ 225$ plus tax) so I can replace it as soon as possible.

I am enclosing a copy of my receipt for the jacket from Southern Sports, Richmond Square Mall.

Sincerely,

Anne J. Thompson

Enclosure

Figure 1. Customer Complaint Letter from Anne Thompson 


\section{White-n-Brite Liquid Bleach Label Directions}

\section{Fabrics}

White-n-Brite Liquid will safely bleach and clean white and most colorfast fabrics including cotton, linen, nylon, dacron, rayon, polyester, and other synthetics including permanent press. For best results, always check manufacturers' care tags and directions for cleaning instructions

Do not use White-n-Brite Liquid on silk, wool, leather, spandex, or blends thereof, or on non-fast colors.

Some fabrics may be treated with finishes that are stain-resistant, water-repellent, or both. Such finishes may require special cleaning procedures. Check manufacturers' care tags and directions for cleaning instructions.

\section{Stains}

Stubborn stains such as coffee and tea, mustard, wine, blood, grass, and perspiration need to be pre-soaked even on appropriate-use fabrics listed above. If bleach is recommended: Immerse the entire article for 5 to 10 minutes in a solution of 1/8 cup bleach per quart of cool water. Rinse well in cool water or run through machine rinse cycle only to stop bleaching action. Then wash according to manufacturer's care tag directions. This procedure cleans and brightens the entire article.

\section{Do not use White-n-Brite Liquid as a spot remover.}

For further information. please contact Carol Smith. Director. Consumer Services Department, Stovall Home Products, 1247 Oak Avenue. St. Louis, MO 00000. Tollfree telephone: 1-000-523-7777. FAX: 000-523-0000.

Figure 2. Directions for Product Use on White-n-Brite Package 


\section{Current Promotions}

\section{Items Available for Use with Consumers}

White-n-Brlte Bleach: Delicates

Introductory single-use packets (lingerie, baby clothes, hosiery)

Carpet-Fresh Pet-Fresh Introductory in-store coupons; $50 \mathbb{c}$ each; one per product purchase

Alr Fair Home Air Freshener New aromas in-store coupons (Sea Air. Autumn Spice. Fresh Pine. Spring Flowers) \$1 off on purchase of any 3 new aromas

Window-Fresh New formula single-use packets

\section{Current Publications, Booklet Rack (Free to Consumers)}

Delicate Fabrics Home Care Guide

White-n-Brite Laundry Tips

White-n-Brite Laundry Tips for Laundromat Users (Great for college students!) White-n-Brite's Permanent Press Laundry Guide White-n-Brite's Tough Stain Tips Pets in the House: Carpet and Floor Care Tips Air Fair Freshener Tips

Figure 3. Promotions and Publications Available to Consumers 


\section{Assignment}

Assume the role of a new hire at Stovall Home Products who is participating in a customer perspective rotation in the Consumer Services Department. Draft the letter to Ms. Anne J. Thompson for Helen Anderson's review. Thompson's address is 2567 Gulf Shores Way, Tallahassee, FL ooooo. Stovall Home Products is located at 1247 Oak Avenue, St. Louis MO ooooo. 